\title{
O processo de especialização produtiva dos agricultores familiares da Zona Sul do Rio Grande do Sul através do Pronaf- custeio
}

\author{
Marcelo Antonio Conterato \\ Universidade Federal do Rio Grande do Sul - Porto Alegre - Rio Grande do Sul - \\ Brasil \\ Cauê Assis Bráz \\ Universidade Federal do Rio Grande do Sul - Porto Alegre - Rio Grande do Sul - \\ Brasil
}

\begin{abstract}
Resumo
A pesquisa tem como foco apontar o contexto do crescimento da soja na Zona Sul a partir da análise do Programa Nacional de Fortalecimento da Agricultura Familiar (Pronaf) e dos valores financiados pelos contratos firmados na região. Utilizando-se da Matriz de Dados do Crédito Rural (MDCR) e da Produção Agrícola Municipal (PAM), é possível verificar as mudanças da produção agrícola regional e seus impactos nos agricultores familiares. Uma política pública como o Pronaf tem o objetivo de fortalecer o pequeno produtor rural e, por consequência, diminuir a especialização produtiva reduzindo as desigualdades na agricultura brasileira. Entretanto, a atuação do programa não segue para este caminho. Nota-se que os contratos analisados indicam o afastamento das premissas definidas na criação do Pronaf em 1996. Dessa forma, o programa colabora para o aprofundamento das desigualdades na agricultura familiar tendo como principal fenômeno o afunilamento da produção agrícola local nas lavouras de soja resultando na especialização destes agricultores.
\end{abstract}

Palavras-chave: Desenvolvimento Rural. Agricultura familiar. Pronaf. Especialização Produtiva.

The process of productive specialization of family farmers in the Southern Zone of Rio Grande do Sul through Pronaf-costing

\begin{abstract}
The research focuses on the context of soybean growth in the South Zone, based on the analysis of the National Program for Strengthening Family Agriculture (Pronaf) and the values financed by the contracts signed in the region. Using the Rural Credit Data Matrix (MDCR) and Municipal Agricultural Production (PAM), it is possible to verify changes in regional agricultural production and its impacts on family farmers. A public policy such as
\end{abstract}


Pronaf has the objective of strengthening small rural producers and, consequently, reducing productive specialization by reducing inequalities in Brazilian agriculture. However, the program does not follow this path. It should be noted that the contracts analyzed indicate that the premises defined in the creation of Pronaf in 1996 were deviated. In this way, the program contributes to the deepening of inequalities in family agriculture, with the main phenomenon being the bottleneck of local agricultural production in soybean crops, resulting in specialization of these farmers.

Keywords: Rural Development. Family Agriculture. Pronaf. Productive Specialization.

\section{El proceso de especialización productiva de los agricultores familiares de la Zona Sur de Rio Grande do Sul a través del Pronaf-costeo}

\section{Resumen}

La investigación tiene como foco apuntar el contexto del crecimiento de la soja en la Zona Sur a partir del análisis del Programa Nacional de Fortalecimiento de la Agricultura Familiar (Pronaf) y de los valores financiados por los contratos firmados en la región. Utilizando la Matriz de Datos del Crédito Rural (MDCR) y la Producción Agrícola Municipal (PAM), es posible verificar los cambios de la producción agrícola regional y sus impactos en los agricultores familiares. Una política pública como el Pronaf tiene el objetivo de fortalecer al pequeño productor rural $\mathrm{y}$, por consiguiente, disminuir la especialización productiva reduciendo las desigualdades en la agricultura brasileña. Sin embargo, la actuación del programa no sigue para este camino. Se observa que los contratos analizados indican el alejamiento de las premisas definidas en la creación del Pronaf en 1996. De esta forma, el programa colabora para la profundización de las desigualdades en la agricultura familiar teniendo como principal fenómeno el hundimiento de la producción agrícola local en las labranzas de soja resultando en la especialización de estos agricultores.

Palabras clave: Desarrollo Rural. Agricultura familiar. Pronaf. Especialización Productiva.

\section{Introdução}

O processo de especialização produtiva, mais especificadamente aquilo que se convencionou chamar commoditização da agricultura familiar, especialmente representado pelo crescente aumento do cultivo de soja no pampa gaúcho a partir dos anos 2000 e sua relação com o Programa Nacional de Fortalecimento da Agricultura Familiar (Pronaf) na sua linha de crédito custeio agrícola será o fio condutor deste artigo. Para tal é feita a análise evolutiva do Pronaf, de suas origens em 1996 até o atual momento, buscando entender as contradições internas existentes no grupo de agricultores familiares que acessam o programa, especialmente o crédito rural do Pronaf na linha custeio agrícola. Traçando um panorama geral dos últimos anos, a pesquisa almeja mostrar a estrutura de produção agrícola municipal em parcela importante da região pampeana gaúcha para identificar o grau de especialização produtiva através da observação do valor da produção de diversos produtos agrícolas utilizando os dados da Produção Agrícola Municipal de 2016. O trabalho utiliza o valor financiado pelo Pronaf-custeio agrícola no período entre 2013 e 2017 com as informações expostas na Matriz de Dados de Crédito Rural do Banco Central do Brasil.

Criado em 1996, o Pronaf surgiu para promover o desenvolvimento sustentável do segmento rural constituído pelos agricultores familiares. Segundo 
Bianchini (2015), o programa direciona linhas de financiamento diferenciadas para este setor consolidando-se como a política de crédito do pequeno agricultor brasileiro. Desde seu surgimento, o Pronaf tem como proposta a melhoria do meio rural, possibilitando com que o pequeno agricultor acesse linhas de crédito para produzir e gerar renda. Entretanto, ao verificar a distribuição dos recursos nota-se que o programa se distancia das premissas que inspiraram sua criação porque os dados apontam que os produtores que acessam o Pronaf estão se especializando em um gênero agrícola.

A agricultura familiar, em tese, apresenta-se como a alternativa para dinamizar o meio rural, a partir da diversificação das atividades agrícolas e não agrícolas geradoras de renda. A Zona Sul do Rio Grande do Sul tem um grande número de agricultores familiares, porém, nos últimos anos, observa-se o avanço de um cultivo novo, até pouco tempo não compatível com as práticas produtivas do agricultor familiar, a soja, um produto agrícola não exclusivamente alimentar.

Neste cenário é importante refletir sobre o fenômeno que se passa na produção de alimentos na região nos últimos anos, qual seja, o avanço das lavouras de soja. A produção agrícola do sul do estado concentra-se entre o arroz e a soja, com acentuado crescimento do último a partir da metade da década de 2000. Os repasses do Pronaf-custeio agrícola tem sido direcionados principalmente para a produção de soja. Conforme Gazolla e Schneider (2013), isso resulta num círculo vicioso que favorece o produtivismo setorial a partir de um estreitamento dos produtos que podem ser cultivados. Por região do Brasil já existe uma diferença significativa nos repasses.

A Tabela 1 expõe que a Região Sul concentra dois terços dos contratos firmados pelo Pronaf e mais de 70\% dos valores liberados entre 2013 e 2017 . Somados, os valores das regiões Nordeste, Norte e Centro-oeste alcançam a marca de $11 \%$ do total liberado para custeio do programa ao longo desses cinco anos. Em razão disso, Pires (2013) aponta que o programa é inerte por atuar como uma política pública de concessão de crédito para a agricultura familiar que mantem as assimetrias internas do setor. Isto ocorre devido o fortalecimento dos desequilíbrios entre os grupos ${ }^{1}$ do Pronaf privilegiando os agricultores familiares que retornam os financiamentos feitos em suas lavouras que, por sua vez, contribuem para a concentração produtiva local reduzindo a diversificação da atividade agrícola contrariando o motivo gerador do programa na década de 1990.

\footnotetext{
${ }^{1} \mathrm{O}$ Manual de Crédito Rural divide os agricultores familiares "pronafianos" em quatro grupos: Grupo A, assentados(as) pelo Programa Nacional de Reforma Agrária (PNRA) com limite de crédito de R\$ 25 mil por agricultor e juros de 0,5\% ao ano; Grupo B, aqueles com renda bruta familiar não superior a R\$ 20 mil que não contratam trabalho assalariado permanente com limite de $\mathrm{R} \$ 4$ mil por operação e juros de 0,5\% ao ano; Grupo A/C, agricultores egressos do Grupo A com limite de crédito de $\mathrm{R} \$$ 7,5 mil por operação e juros de 1,5\% ao ano; Grupo Variável, agricultores familiares que não detenham área superior a quatro módulos fiscais obtendo, no mínimo, 50\% da renda bruta familiar da exploração agropecuária e não agropecuária do estabelecimento com limite de $\mathrm{R} \$ \mathbf{2 5 0}$ mil por operação e juros entre $2,5 \%$ ao ano e 5,5\% ao ano (Banco Central do Brasil, 2018).
} 
Tabela 1. Contratos e valores financiados pelo Pronaf-custeio (2013-2017)

\begin{tabular}{cccc}
\hline Região & Contratos $(\mathrm{A})$ & Valor $(\mathrm{B})$ em milhões & $(\mathrm{B}) /(\mathrm{A})$ \\
\hline Sul & 1.894 .277 & $36.673,25$ & $19.360,03$ \\
Sudeste & 499.472 & $9.607,84$ & $19.236,00$ \\
Nordeste & 243.527 & $2.403,71$ & $9.870,40$ \\
Norte & 77.369 & $1.484,60$ & $19.188,56$ \\
Centro-Oeste & 143.365 & $3.488,46$ & $24.332,70$ \\
\hline Brasil & 2.858 .010 & $53.657,86$ & \\
\hline
\end{tabular}

Fonte: MDCR - BCB (Dados organizados pelos autores).

A paisagem do bioma pampa tem sido alterada pelo avanço das lavouras de soja. Isso é resultado de um aprofundamento da especialização produtiva local. Neste cenário, o fomento às atividades econômicas de uso sustentável é elemento essencial para assegurar a conservação do pampa nos municípios da região. Diversificar a produção é fundamental para assegurar a conservação da biodiversidade e o desenvolvimento econômico e social (MMA, 2017). Principalmente, buscar estratégias para evitar o processo de especialização produtiva que o Pronaf executa ao direcionar grande parte dos agricultores familiares para o cultivo de soja.

O trabalho apresenta uma parte analítica sobre o Pronaf e outra histórica sobre a Zona Sul, traçando um perfil regional ao longo dos anos e analisando aspectos ambientais e estruturais da produção agropecuária regional. Posteriormente, é exposta a delimitação metodológica em que se explica como foi feita a coleta de dados e a seleção dos municípios. Em seguida, são apresentados os resultados da pesquisa e como a atividade agrícola financiada pelo Pronaf-custeio tem sido conduzida. Por fim, as conclusões do trabalho.

\section{Dinâmica do Pronaf e seu financiamento na Zona Sul}

Na sua criação, na década de 1990, o Pronaf se apresentou como uma política pública de fortalecimento do agricultor familiar, dando robustez à produção de alimentos e ampla capacidade de abastecimento do mercado consumidor nacional. Depois de duas décadas, alguns resultados apresentados nesta pesquisa apontam que o programa se afasta de sua proposta inicial e colabora, de fato, para o fortalecimento das desigualdades da agricultura local, especialmente através da especialização produtiva. Com isso, os resultados devem ser analisados com preocupação (AQUINO; SCHNEIDER, 2011).

De acordo com Copetti (2008), as regiões onde o Pronaf é acessado apresentam erosão do solo e aumento de contaminação pelo uso de agrotóxicos. Além dos impactos ambientais, o programa exclui muitos agricultores por impor restrições ao ingresso no processo de financeirização. Um desses limitadores é o fato de nem todo município ter agências para resolver os trâmites burocráticos.Outro fator que dificulta a cobertura do Pronaf para os agricultores menos capitalizados é a falta de contato com o sistema bancário e, por isso, os agricultores não tem condições de cumprir as metas impostas para os contratos de financiamento. O último fator refere-se ao fato de o programa já surgir direcionado 
para um público que já está integrado aos mercados e, assim, o Pronaf exclui aqueles que deveria acolher.

Por sua vez, Guanzirolli (2007) explicita que o programa tem como foco o agricultor familiar integrado ao modelo agrícola que cresceu no período da Modernização Conservadora nas décadas de 1960 e 1970. Com isso, tem-se a liberação de montantes cada vez maiores para a produção de soja enquanto a produção de alimentos, que abastece o mercado interno, tem o financiamento reduzido. O Pronaf privilegia os estabelecimentos eficientes. Essa eficiência é quantificada pelo aumento da produção de commodities que mostram o direcionamento das lavouras para uma especialização.

Através do comportamento da variação do valor da produção é possível afirmar que os municípios foram direcionados para a monocultura. Quando a soja não está presente enquanto cultivo especializado, ela apresenta-se como cultivo auxiliar. Esse comportamento é observado na Tabela 4 (apresentada na seção 4.1) tomando como exemplo o município de Santa Vitória do Palmar. Sua principal atividade é a cultura de arroz. Em 2007, este cultivo representava quase $100 \%$ dos produtos cultivados nesse município. Entretanto, no período analisado houve queda dessa cultura na participação do valor da produção municipal, sendo este espaço ocupado pela soja. De acordo com os dados, esse movimento foi comum no período recente em outros municípios da região.

Em termos de sustentabilidade isso é preocupante, pois Paulino e Kruger (2009) evidenciam que oposição de dois modelos ${ }^{2}$ inversamente proporcionais na dinâmica produtiva. A forma que se desenvolve a agricultura na Zona Sul torna o cultivo de alimentos destinados para o abastecimento interno uma prática acessória à produção de commodities que se expandem cada vez mais ao longo dos últimos anos. Godoi, Búrigo e Cazella (2016) acreditam que insistir no modelo produtivista não é sustentável porque não viabiliza as características de reprodução social dos atores locais.

Flexor e Leite (2017) indicam outros fatores relevantes no decorrer desta dinâmica do modelo monocultor, o uso dos recursos naturais, terra e água são exauridas pelas lavouras de soja, e os proprietários dos estabelecimentos rurais perdem sua autonomia pelo aumento de dependência da demanda externa do mercado agrícola. Cunha (1994) aponta que na busca de torna os solos produtivos aumenta-se o aporte de capital acarretando no consumo de fertilizantes e outros produtos químicos agressivos a natureza.

Ocorre ainda o processo de "estrangeirização de terras", comum ao Cone Sul, onde as condições para o plantio de soja são similares. Nos cinco países ${ }^{3}$, a principal atividade no espaço rural é a produção de soja. Nessa região, parte significativa das terras é controlada pelas mesmas empresas estrangeiras fazendo com que as fronteiras dos Estados nacionais não sejam relevantes sendo sua existência mera formalidade porque na práticao que existe é uma República Unida da Soja conforme campanha publicitária da Syngenta (WESZ JÚNIOR, 2016)

\footnotetext{
${ }^{2} \mathrm{~A}$ agricultura brasileira, desde suas origens, coloca de um lado o modelo patronal, monocultor e produtivista, e do outro o familiar, policultor e pluriativo. (DELGADO, 2012; SCHNEIDER; CASSOL, 2013; SCHNEIDER, 2018).

3 Os países são Argentina, Bolívia, Brasil, Paraguai e Uruguai.
} 
Segundo Wesz Júnior (2014), a presença do capital financeiro é cada vez maior nas lavouras de soja. Isto compromete a produção a partir das dívidas que os estabelecimentos agropecuários adquirem ao se financiar. Assim, procuram o cultivo mais rentável para pagar o financiamento e gerar a sua renda, ou seja, aumenta-se a produção de commodities por serem produtos agrícolas de comercialização mais fácil a partir da exportação. Ainda mais quando ações setoriais, políticas de subsídio e fomento à produção, e não setoriais, políticas conjunturais que impactam as relações: trabalhistas, ambientais e produtivas, colaboram para a produção do grão sustentando o seu perfil agroexportador.

Vennet, Schneider e Dessein (2015) apontam que as frequentes práticas da agricultura convencional são insustentáveis. A mudança na paisagem causada somada aos problemas ambientais que já foram citados anteriormente que acarretam na redução da biodiversidade são prejudiciais aos agricultores familiares das diferentes categorias, sendo elas, agricultores colonos, agricultores de nicho e empresários da agricultura familiar.

Os agricultores familiares são os que possuem forte relação com a terra, os de nicho atuam de acordo com a necessidade, apresentando a vantagem de produzir tanto produtos convencionais quanto orgânicos e, por último, os empresários da agricultura familiar apresentam um perfil fortemente produtivista que se encaixa com o caráter majoritário do Pronaf. No Rio Grande do Sul, 30\% das lavouras de soja são produzidas por essas três categorias de agricultores de acordo com Vennet, Schneider e Dessein (2015). A partir disso, nota-se que na prática o Pronaf está totalmente afastado das suas intenções iniciais. Delgado (2012) também aponta que o padrão de financiamento concentrado nos produtores capazes de integrar a rentabilização do capital e implementar tecnologia durante o cultivo gerou a centralização de recursos financeiros. Essa dinâmica teve início ao longo dos anos 1970 nos estabelecimentos produtores de grãos, como milho e soja.

A grande contradição do Pronaf situa-se entre escolher um modelo que promove a diversificação da produção ou um que adota os mesmos moldes do agronegócio ao especializar suas lavouras em um cultivo só, que apenas se encaixa nos moldes da pequena empresa familiar ou aqueles que podem ser chamados de agricultores familiares consolidados que pertencem ao Grupo Variável. Quando a maior parte dos financiamentos é direcionada para os grupos mais capitalizados, o programa sinaliza que não tem ações para alterar a estrutura de produção agrícola. Assim, o programa privilegia atividades produtivas e cultivos com inserção nas tradicionais cadeias. O aumento dos repasses resulta num círculo vicioso que favorece o produtivismo setorial a partir de um estreitamento dos produtos que podem ser cultivados (GAZOLLA; SCHNEIDER, 2013).

A especialização dos agricultores "pronafianos" é analisada por Tolentino (2017) como uma forma descentralizada de fomento do agronegócio porque a lógica produtivista não condiz com a proposta de promoção de desenvolvimento local de quando o Pronaf foi elaborado. Quando o pequeno produtor com grande potencial de executar a pluriatividade torna-se agricultor full time, o programa afirma que, na prática, está barateando a mão de obra da agricultura convencional adotando agricultores familiares para produzir o mesmo leque de produtos do agronegócio que é bastante reduzido. Não converge, portanto com o objetivo inicial de redução das desigualdades, uma vez que concentra e aumenta a produção 
dos agricultores familiares dos grupos mais capitalizados. Wesz Júnior (2014) mostra que em estabelecimentos menores de 100 hectares, a produção está cada vez mais direcionada para o cultivo de soja indo ao encontro do conceito apresentado por Guanzirolli (2007) de tornar os estabelecimentos eficientes.

Logo, o Pronaf está fortalecendo o agricultor do Grupo Variável dando ênfase ao modelo produtivista de lidar com o espaço rural. Nos últimos anos, mais de $70 \%$ dos recursos foram adquiridos pelos agricultores do Sul que são os produtores que cultivam as lavouras com maior inserção no mercado de commodities como soja e milho. Com isso, o Pronaf acaba fazendo "mais do mesmo" na agricultura local ao optar por agricultores familiares capazes de manter cultivos que são caracterizadas pelo uso intensivo de fertilizantes, agrotóxicos, sementes melhoradas e máquinas, sendo este o caso das lavouras de soja que se espalharam na Zona Sul do Rio Grande do Sul nos últimos anos (GUANZIROLLI, 2007; AQUINO; SCHNEIDER, 2011; GAZOLLA; SCHNEIDER, 2013; GRISA; WESZ JÚNIOR; BUCHWEITZ, 2014; GRISA, 2017; TOLENTINO, 2017).

\subsection{A Zona Sul do Rio Grande do Sul}

Historicamente vinculada com atividades econômicas do primeiro setor, a Zona Sul, de acordo com PTDRS (2009), é caracterizada pela concentração da posse da terra e baixa densidade populacional que sinalizam o atraso regional em relação ao resto do estado. A região situa-se sobre o bioma pampa que é um ecossistema campestre com vegetação predominantemente de gramíneas e alguns arbustos espalhados e dispersos. Neste bioma os campos nativos são predominantes, mas há também a presença de matas ciliares, matas de encosta, matas de pau-ferro, formações arbustivas, butiazais e banhados (IBGE, 2004).

Atualmente, esse ecossistema está em risco devido às mudanças climáticas, demográficas e agroalimentares. Principalmente pelo fato de sua vegetação original ser substituída pela lavoura de soja, dado o aumento da fronteira agrícola. A expansão de monoculturas descaracterizam as paisagens naturais desse ecossistema. Observa-se um processo generalizado na região decorrente da agressividade das mudanças geradas pelo avanço da soja, tal como a arenização. Diante deste cenário, o fomento às atividades econômicas de uso sustentável é elemento essencial para assegurar a conservação do pampa. A diversificação da produção rural é o caminho para assegurar a conservação da biodiversidade e o desenvolvimento econômico e social (BRASIL, 2017).

O debate sobre o atraso da região sul é antigo e Bandeira (1994) expõe que a decadência regional tem duas dimensões. A primeira dimensão é referente à especialização da atividade primária, a pecuária, que vigorava desde o Brasil Colonial. Na metade do século passado, a pecuária, que era base exportadora da região, entrou em uma profunda crise e os donos das terras não destinaram seus recursos para outras atividades produtivas gerando estagnação. A segunda dimensão é a industrialização frustrada. A região não foi capaz de manter e diversificar a indústria que surgia em meados da década de 1910. Assim, estrangulou-se o crescimento industrial.

Desde meados do século XVIII, a região caracterizou-se pela pecuária ser a atividade predominante no campo. Essa característica é fruto do Rio Grande do Sul 
servir como exportador para o mercado interno do país, principalmente com o charque (FURTADO, 2005). O abastecimento do país era viável pela existência das grandes estâncias produtoras de charque. A existência desse tipo de estabelecimento rural é a principal explicação para a concentração de recursos para a produção de carne. O processo de formação do latifúndio pautou-se na compra do gado e dos campos de agricultores com propriedades menores sem condições de manter as fazendas em virtude de seu empobrecimento. Isso tornou o pequeno proprietário de terras um proletário do campo. Por sua vez, o grande proprietário de terra administrava seus recursos de modo a manter seu comportamento pouco empreendedor aglutinando terras de fazendeiros empobrecidos a fim de manter seu negócio inalterado. Dessa forma, Bandeira (1994) descreveu como a região especializou-se em produzir carne.

Ao analisar comportamentos de agentes econômicos, Bandeira (1994) aponta que existem dois tipos, o comportamento otimizador e o satisfatório. $\mathrm{O}$ comportamento otimizador é aquele encontrado nos manuais de ciências econômicas, o homo economicus, que é onisciente e sempre toma as melhores decisões. Enquanto isso, o comportamento satisfatório corresponde ao mundo real cujo agente busca mais segurança e reduzir seus riscos. Dito isso, pode-se deduzir que os latifundiários aproximavam-se do comportamento satisfatório. Dessa forma, afastavam-se dos riscos de perdas de capital com o investimento em novos modelos de negócio, alternativas de produção e de tecnologia. Preferiam uma rentabilidade mais baixa, porém garantida. Isso foi realizado com o arrendamento de terra dos fazendeiros pobres para manutenção do alto padrão de vida dos latifundiários. Essa especialização forçada na pecuária impediu a diversificação das linhas de produção.

A região registra baixo dinamismo desde a década de 1940. Benetti (1994) apresenta dados sobre a modernização da agropecuária na região a partir de 1965. Este ano foi marcado pelo ingresso do pacote tecnológico intensivo em capital que inseriu a lavoura empresarial nos cultivos de arroz e soja. Bandeira (1994) menciona que o arroz era uma atividade complementar à pecuária no início do século $X X$. $A$ partir da década de 1960 surgem mudanças relevantes na estrutura produtiva local.

A expansão da área cultiva com soja foi seguida pela expansão do arroz entre as décadas de 1960 e 1980. Inicialmente, a prosperidade nas lavouras da região canalizou-se no cultivo da soja com a instalação de um pacote tecnológico intensivo em capital. O surto de crescimento proporcionado pela soja na época foi tão envolvente que chegou a se considerar que toda a região se desenvolveria a partir do cultivo da soja e que a pastagem nativa seria explorada economicamente pelos fazendeiros responsáveis pelas lavouras de soja. Entretanto, o desenvolvimento da soja frustrou-se no meio da década de 1970 e o cultivo responsável em transformar o fazendeiro local em verdadeiro empresário capitalista foi o do arroz que, a partir da década de 1980, rompeu com as formas arcaicas de produção local (BENETTI, 1994).

No período, o perfil produtivo da estância foi alterado apesar do antagonismo. Benetti (1994) assinala que muitos pecuaristas migraram para o cultivo de arroz, dado os ganhos significativos de produtividade das lavouras. Por outro lado, muitos arrozeiros começaram a dedicar-se à pecuária. $O$ resultado foi a integração das atividades que, anteriormente, opunham-se. A integração da pecuária com a agricultura aumentou o nível de produção global, porém o 
crescimento econômico foi guiado pela concentração de terra e produção de poucos produtos.

A Tabela 2 apresenta a presença da agricultura familiar nos municípios da região. Nota-se que os municípios possuírem mais estabelecimentos agropecuários da agricultura familiar, entretanto com áreas de cultivo reduzidas. Aceguá, Arroio Grande, Bagé, Capão do Leão, Dom Pedrito, Jaguarão, Lavras do Sul, Pedras Altas, Pinheiro Machado e Santa Vitoria do Palmar são alguns dos municípios em que essa discrepância se apresenta de forma mais acentuada. No período recente, um fator que colabora para o avanço desse cultivo é o aumento do preço das terras do norte do estado que, paralelamente, foi acompanhado pela desvalorização da pecuária local que é a herança das estâncias charqueadoras.

Tabela 2. Participação da agricultura familiar nos municípios da Zona Sul do Rio Grande do Sul

\begin{tabular}{|c|c|c|c|c|}
\hline Municípios & $\begin{array}{l}\text { Estabelecimentos } \\
\text { Agropecuários }\end{array}$ & $\begin{array}{l}\text { Agricultura } \\
\text { Familiar (\%) }\end{array}$ & Área Total & $\begin{array}{l}\text { Agricultura } \\
\text { Familiar (\%) }\end{array}$ \\
\hline Aceguá & 726 & $73,14 \%$ & 103.500 & $13,91 \%$ \\
\hline Amaral Ferrador & 1.121 & $78,86 \%$ & 37.735 & $45,27 \%$ \\
\hline Arroio do Padre & 507 & $95,86 \%$ & $9 \cdot 918$ & $92,22 \%$ \\
\hline Arroio Grande & 825 & $67,88 \%$ & 147.171 & $15,56 \%$ \\
\hline Bagé & 1.198 & $59,52 \%$ & 302.530 & $5,75 \%$ \\
\hline Caçapava do Sul & 3.385 & $77,90 \%$ & 231.896 & $28,70 \%$ \\
\hline Candiota & 716 & $90,50 \%$ & 49.563 & $29,89 \%$ \\
\hline Canguçu & 9.881 & $88,81 \%$ & 278.409 & $50,05 \%$ \\
\hline Capão do Leão & 240 & $59,17 \%$ & 59.096 & $4,64 \%$ \\
\hline Cerrito & 1.003 & $83,55 \%$ & 37.004 & $41,31 \%$ \\
\hline Chuí & 43 & $53,49 \%$ & 14.656 & $9,91 \%$ \\
\hline Dom Pedrito & 1.410 & $50,57 \%$ & 414.135 & $5,48 \%$ \\
\hline Herval & 1.175 & $77,53 \%$ & 147.751 & $22,24 \%$ \\
\hline Hulha Negra & 1.032 & $84,11 \%$ & 49.726 & $42,18 \%$ \\
\hline Jaguarão & 675 & $65,19 \%$ & 172.390 & $9,44 \%$ \\
\hline Lavras do Sul & 882 & $66,67 \%$ & 200.372 & $8,54 \%$ \\
\hline Morro Redondo & 727 & $89,55 \%$ & 14.617 & $75,27 \%$ \\
\hline Pedras Altas & 524 & $72,14 \%$ & 108.985 & $9,53 \%$ \\
\hline Pedro Osório & 198 & $59,09 \%$ & 46.198 & $5,18 \%$ \\
\hline Pelotas & 3.596 & $89,43 \%$ & 105.960 & $48,87 \%$ \\
\hline Pinheiro Machado & 1.642 & $70,52 \%$ & 214.506 & $19,57 \%$ \\
\hline Piratini & 2.910 & $77,39 \%$ & 286.890 & $26,79 \%$ \\
\hline Rio Grande & 1.214 & $74,22 \%$ & 170.148 & $8,81 \%$ \\
\hline Santana da Boa Vista & 1.633 & $81,87 \%$ & 102.766 & $37,82 \%$ \\
\hline Santa Vitória do Palmar & 805 & $54,66 \%$ & 291.217 & $7,56 \%$ \\
\hline São José do Norte & 1.999 & $90,40 \%$ & 62.276 & $45,03 \%$ \\
\hline São Lourenço do Sul & 4.327 & $88,10 \%$ & 171.900 & $44,83 \%$ \\
\hline Tavares & 982 & $88,39 \%$ & 45.756 & $40,40 \%$ \\
\hline Turuçu & 441 & $89,57 \%$ & 20.547 & $31,66 \%$ \\
\hline Média & & $80,95 \%$ & & $21,33 \%$ \\
\hline
\end{tabular}

Fonte: Censo Agropecuário 2006 (IBGE - Dados organizados pelos autores). 
Em economia, alguns acontecimentos se repetem e a Zona Sul não ficou excluída desse processo. Os últimos anos apresentam uma nova expansão do cultivo de soja. A Tabela 3 apresenta a variação percentual da cultura, entre os anos de 2007 e 2016, para área plantada e valor da produção. Os dados confirmam que a região vive seu segundo ciclo de produção de soja pelo crescimento generalizado da área plantada e do valor produzido em cada município.

Tabela 3. Soja: variação da área plantada e do valor da produção entre 2007 e 2016 (\%)

\begin{tabular}{lcc}
\hline \multicolumn{1}{c}{ Municípios } & Área plantada & Valor da produção \\
\hline Aceguá (RS) & 53,39 & 40,99 \\
Amaral Ferrador (RS) & 11,23 & 3,04 \\
Arroio do Padre (RS) & 13,54 & 0,43 \\
Arroio Grande (RS) & 31,35 & 9,18 \\
Bagé (RS) & 39,62 & 16,24 \\
Caçapava do Sul (RS) & 29,39 & 8,31 \\
Candiota (RS) & 70,28 & 55,14 \\
Canguçu (RS) & 33,50 & 2,73 \\
Capão do Leão (RS) & 23,31 & 12,41 \\
Cerrito (RS) & 53,95 & 49,34 \\
Chuí (RS) & 27,35 & 9,28 \\
Dom Pedrito (RS) & 17,00 & 7,03 \\
Herval (RS) & 63,71 & 38,49 \\
Hulha Negra (RS) & 63,06 & 53,22 \\
Jaguarão (RS) & 39,15 & 24,01 \\
Lavras do Sul (RS) & 22,71 & 20,09 \\
Morro Redondo (RS) & 39,18 & 3,45 \\
Pedras Altas (RS) & 64,84 & 49,71 \\
Pedro Osório (RS) & 43,90 & 24,57 \\
Pelotas (RS) & 28,28 & 5,28 \\
Pinheiro Machado (RS) & 33,73 & 17,24 \\
Piratini (RS) & 53,43 & 45,42 \\
Rio Grande (RS) & 11,29 & 4,60 \\
Santana da Boa Vista (RS) & 42,59 & 30,29 \\
Santa Vitória do Palmar (RS) & 22,82 & 8,19 \\
São José do Norte (RS) & - & - \\
São Lourenço do Sul (RS) & 18,09 & 3,27 \\
Tavares (RS) & 3,86 & 0,37 \\
Turuçu (RS) & 29,54 & 21,90 \\
\hline Total & 35,15 & \\
\hline Fon & PAM & \\
\hline & & \\
\hline
\end{tabular}

Fonte: PAM 2016 (IBGE - Dados organizados pelos autores).

Os dados revelam que nos últimos anos a produção de soja cresceu de forma significativa na Zona Sul, apontando uma nova tendência de concentração produtiva na região. Feix, Leusin Júnior e Agranonik (2017) revelam que o presente avanço da soja em pastagens nativas do bioma local tem ocorrido devido às vantagens econômicas apresentadas por essa cultura em relação à outras lavouras e à pecuária. Moreira (2019) acrescente que além de avançar sobre os campos do 
pampa, a criação pecuária, com o gado de corte, migra para as margens da floresta amazônica colaborando para o desmatamento e provocando mais conflitos por terra. No fim, o avanço da soja no pampa gera externalidades negativas em espaços de outros biomas do Brasil.

Conforme Kuplich, Capoane e Costa (2018), o avanço das lavouras de soja na metade Sul do Rio Grande do Sul alterou o perfil das áreas tradicionalmente utilizadas na produção pecuária e também da cultura do arroz, que está em fase de transição, passando do modelo mono ou binomial (arroz-pousio ou arroz-pecuária), para um sistema misto com as culturas de grãos como soja, milho e trigo. A conversão acelerada das áreas de campo nativo para lavouras de soja configura uma realidade preocupante para o pampa na atualidade. Seguindo o trabalho de Moreira (2019), as principais consequências de assumir a produção da soja como principal produto agrícola é trocar formas tradicionais de trabalhar a terra por atividades que atendem interesses econômicos globais, ou seja, toda a dinâmica de mercado é adaptada pelos produtores locais e, com isso, a autonomia produtiva é bastante reduzida. Ademais, registra-se que o monocultivo acentua a concentração de terra, o uso de agrotóxicos, reduz biodiversidade e as áreas de pastagens naturais forçando a retirada do gado de corte da região.

\section{Metodologia}

A análise da especialização regional recolheu as colaborações de Garagorry, Alves e Souza (2003) a respeito da especialização na agricultura brasileira. Para tal, optou-se por classificar os tipos de especialização em detrimento da dominância produtiva adaptando para os dados coletados. Os municípios que possuem um alto grau de especialização tem uma produção mais voltada aos mercados em que a monocultura é predominante. A escolha pelos municípios com especialização alta tem como finalidade analisar o financiamento da produção dos agricultores vinculados ao Pronaf ${ }^{4}$ e observar se a produção municipal gera impacto nos agricultores familiares. Por isso os municípios analisados são os especializados em uma ou duas culturas agrícolas.

Para tal, definiu-se dois tipos de especialização. O primeiro, Tipo 1, ocorre quando o percentual do valor da produção de uma atividade agrícola supera $80 \%$. 0 segundo, Tipo 2, é percebido quando a soma de duas atividades agrícolas alcança $90 \%$ do valor de produção tendo um produto com participação superior a $50 \%$ e outro superior a 10\%. Resumindo, tem-se que:

- Tipo 1: especialização em uma atividade

$(\mathrm{y} 1 \%)>80 \%$.

- Tipo 2: especialização em duas atividades

$50 \%<(y 1 \%)<80 \%+(y 2 \%)>90 \%$, se $(y 2 \%)>10 \%$

${ }^{4} \mathrm{O}$ programa tem como finalidade fomentar a diversificação de atividades geradoras de renda do agricultor familiar. Seus beneficiários são os produtores rurais que compõem a Declaração de Aptidão ao Pronaf (DAP). 
Ambos indicadores apresentam dominância simples de acordo com Garagorry, Alves e Souza (2003) em que não há presença de diversidade produtiva, ou seja, há concentração e, portanto, especialização da produção municipal em algum produto agrícola.

A importância de tipificar a especialização produtiva dos municípios é tornar possível instrumentalizar uma forma de análise da produção local. Segundo Kageyama (2004), quando existe concentração dos recursos físicos, terra e trabalho, e financeiros, capital, para produzir tem-se o direcionamento a um alto grau de dependência ao exercício de uma ou duas atividades agrícolas que reduzem a autonomia dos produtores locais. De acordo com a pesquisadora, os esforços produtivos são voltados em poucas culturas agrícolas que são intensivas em capital e tecnologia. Com isso, o recente aumento produtivo de muitos agricultores familiares teve como impacto a queda na diversidade produtiva. O pequeno agricultor da região passou a optar por culturas consumidoras de agrotóxicos que colaboram para a degradação ambiental e, simultaneamente, empobrecem o solo.

\subsection{Coleta de dados}

Este trabalho utilizou diversas fontes governamentais para fazer a análise produtiva na região sul do Rio Grande do Sul. Os Censos Agropecuários de 2006 e de 2017 foram importantes para traçar o perfil geral da região analisada na pesquisa. Parte dos dados referentes à produção agrícola é proveniente da Produção Agrícola Municipal (PAM) do IBGE entre os anos de 2007 e 2016. Os dados referentes ao financiamento da produção agrícola foram apanhados na Matriz de Dados de Crédito Rural (MDCR) do Banco Central do Brasil (BCB) para os anos de 2013 e 2017.

A coleta de dados da PAM permitiu verificar o comportamento de sete lavouras temporárias nos vinte e nove municípios. Assim, foram apanhadas informações dos cultivos de arroz (em casca), cebola, feijão (em grão), milho (em grão), soja (em grão), tomate e trigo (em grão). As estatísticas tiveram a finalidade de indicar anualmente, entre 2007 e 2016, em cada município a área plantada em hectares, a quantidade produzida em toneladas e o valor da produção em reais dos cultivos listados.

Por sua vez, a MDCR evidenciou o valor dos contratos do Pronaf-custeio agrícola nos municípios que apresentaram especialização produtiva em soja ou arroz no período. O primeiro ano de divulgação do valor dos contratos por município e produto de atividade agrícola é 2013, portanto o intervalo escolhido para análise dos contratos nestes municípios é de janeiro de 2013 até dezembro de 2017. Os contratos mostram quais cultivos foram financiados pelo Pronaf-custeio nos respectivos anos. A atualização monetária foi feita pelo Índice Nacional de Preços ao Consumidor Amplo (IPCA) para o ano de 2017. 


\subsection{Seleção dos municípios}

Para aplicar os parâmetros de pesquisa, foram elencados 29 municípios do sul do Rio Grande do Sul conforme Figura 1. Os municípios que integram os Coredes 5 Sul e Campanha tiveram sua produção agrícola analisada para verificar a estrutura fundiária e acompanhar os financiamentos do custeio da agricultura familiar através do Pronaf.

\section{Figura 1. Mapa do Rio Grande do Sul - com destaque para os municípios pesquisados}

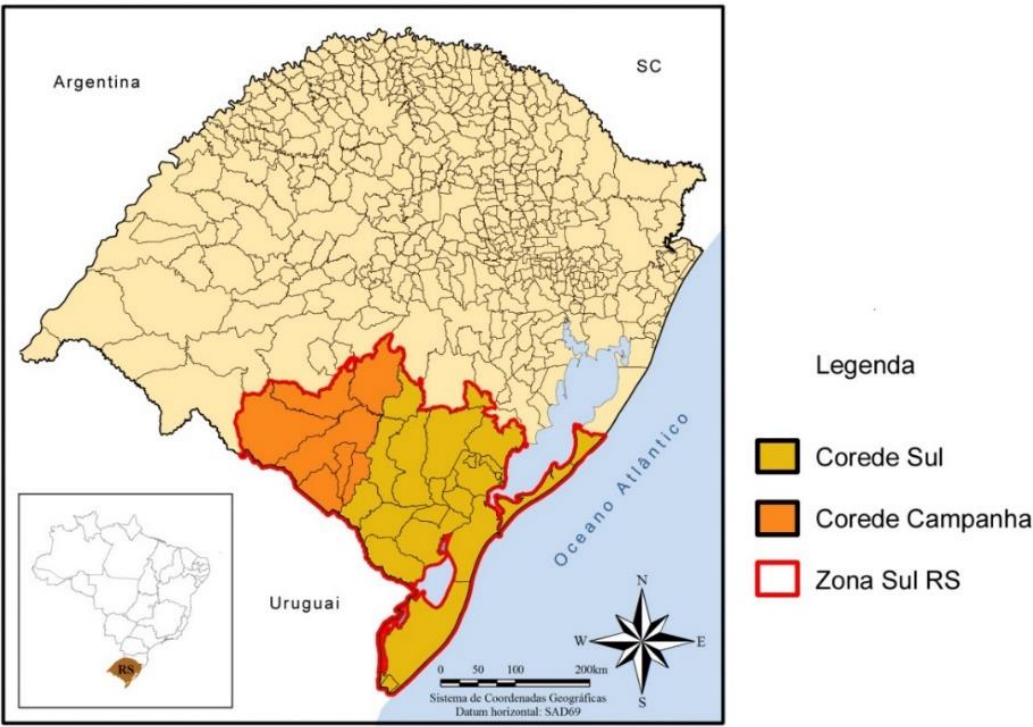

Fonte: FEE Dados (Organizado pelos autores).

O Corede Sul conta com vinte e dois municípios que são: Amaral Ferrador, Arroio do Padre, Arroio Grande, Canguçu, Capão do Leão, Cerrito, Chuí, Herval, Jaguarão, Morro Redondo, Pedras Altas, Pedro Osório, Pelotas, Pinheiro Machado, Piratini, Rio Grande, Santa Vitória do Palmar, Santana da Boa Vista, São José do Norte, São Lourenço do Sul, Tavares e Turuçu.

Os municípios do Corede Campanha são: Aceguá, Bagé, Caçapava do Sul, Candiota, Dom Pedrito, Hulha Negra e Lavras do Sul.

\section{Resultados}

A pesquisa encontrou informações que se dividem em dois campos de análise. Em um campo, foram obtidos dados referentes à produção agrícola e ao uso da terra. No outro, tem-se dados relacionados aos financiamentos do Pronaf-

\footnotetext{
5 Os Conselhos Regionais de Desenvolvimento (Coredes) foram criados pela Lei $n^{\circ} 10.283$, de 17 de outubro de 1994 e têm por objetivo a promoção do desenvolvimento regional, harmônico e sustentável, através da integração dos recursos e das ações de governo na região, visando à melhoria da qualidade de vida da população, à distribuição equitativa da riqueza produzida, ao estímulo à permanência do homem em sua região e à preservação e recuperação do meio ambiente (FEEDADOS, 2015).
} 
custeio agrícola. Juntos, ambos apresentam evidências da especialização produtiva local no período recente.

O Quadro 1 apresenta os municípios que estão inclusos na restrição definida para a análise do comportamento da produção agrícola regional no período entre 2007 e 2016 e os municípios que manifestaram avanço significativo do cultivo da soja, ou seja, duplicação do valor da participação dessa cultura no valor da produção municipal. A especialização no valor da produção agrícola municipal foi percebida em 13 municípios.

A distribuição de municípios especializados nas culturas de soja e de arroz é parecida, seis apresentam algum tipo de especialização em soja e sete em arroz. Apesar de apenas seis municípios serem especializados em soja, observa-se que doze revelaram um crescimento no cultivo da soja, incluindo municípios especializados em arroz. Com isso, o Quadro 1 apresenta os 18 municípios que terão os contratos do Pronaf-custeio agrícola explorados na MDCR.

\section{Quadro 1. Especialização Produtiva nos municípios pesquisados (2007-2016)}

\begin{tabular}{|c|c|c|c|c|}
\hline Municípios & $\begin{array}{c}\text { Presença de } \\
\text { Especialização }\end{array}$ & $\begin{array}{c}\text { Tipo de } \\
\text { Especialização }\end{array}$ & Produção & $\begin{array}{l}\text { Avanço da } \\
\text { Soja }\end{array}$ \\
\hline Aceguá & Sim & 2 & Soja & Sim \\
\hline Arroio Grande & Sim & 1 & Arroz & \\
\hline Bagé & Não & & & Sim \\
\hline Caçapava do Sul & Não & & & Sim \\
\hline Candiota & Não & & & Sim \\
\hline Capão do Leão & Sim & 2 & Arroz & \\
\hline Cerrito & Não & & & Sim \\
\hline Chuí & $\operatorname{Sim}$ & 1 & Arroz & \\
\hline Dom Pedrito & Sim & 2 & Arroz & \\
\hline Hulha Negra & $\operatorname{Sim}$ & 1 & Soja & Sim \\
\hline Jaguarão & Sim & 2 & Arroz & Sim \\
\hline Lavras do Sul & Sim & 2 & Soja & Sim \\
\hline Pedras Altas & Sim & 2 & Soja & Sim \\
\hline Pinheiro Machado & Não & & & Sim \\
\hline Piratini & Sim & 1 & Soja & Sim \\
\hline Rio Grande & Sim & 1 & Arroz & \\
\hline Santana da Boa Vista & $\operatorname{Sim}$ & 1 & Soja & Sim \\
\hline Santa Vitória do Palmar & Sim & 1 & Arroz & \\
\hline
\end{tabular}

Fonte: PAM 2016 (IBGE - Dados organizados pelos autores).

\subsection{Uso da terra}

A Tabela 4 exibe como o cultivo das lavouras temporárias se comportou entre 2007 e 2016. O comportamento geral é que a soja está tomando parcelas maiores na participação do valor produzido. O cultivo de soja avançou em dezessete dos dezoito municípios listados. Enquanto isso a produção de produtos alimentares como cebola, feijão, milho, tomate e trigo alcançou um desempenho deveras insignificante no período. Destaca-se a acentuada queda no valor de produção do milho em Candiota, Cerrito, Hulha Negra e Santana da Boa Vista. 
Tabela 4. Variação do Valor da Produção (2007-2016) (\%)

\begin{tabular}{|c|c|c|c|c|c|c|c|c|c|}
\hline \multirow[b]{2}{*}{ Município } & \multicolumn{9}{|c|}{ Produto das lavouras temporárias } \\
\hline & Anos & Tota & $\begin{array}{l}\text { Arroz } \\
\text { (em } \\
\text { casca) }\end{array}$ & Cebola & $\begin{array}{l}\text { Feijão } \\
\text { (em } \\
\text { grão) }\end{array}$ & $\begin{array}{l}\text { Milho } \\
\text { (em } \\
\text { grão) }\end{array}$ & $\begin{array}{l}\text { Soja } \\
\text { (em } \\
\text { grão) }\end{array}$ & Tomate & $\begin{array}{l}\text { Trigo } \\
\text { (em } \\
\text { grão) }\end{array}$ \\
\hline \multirow{2}{*}{ Aceguá } & $\Delta$ & 100 & $-24,79$ & - & - & $-3,86$ & 40,99 & - & $-3,18$ \\
\hline & 2016 & 100 & 41,99 & - & - & 1,01 & 56,66 & - & 0,3 \\
\hline \multirow{2}{*}{$\begin{array}{l}\text { Arroio } \\
\text { Grande }\end{array}$} & $\Delta$ & 100 & $-8,13$ & - & $-0,02$ & 0,46 & 9,18 & - & $-0,5$ \\
\hline & 2016 & 100 & 80,6 & - & 0,02 & 0,64 & 16,47 & - & 0,22 \\
\hline \multirow{2}{*}{ Bagé } & $\Delta$ & 100 & 4,49 & $-0,06$ & $-0,06$ & $-3,64$ & 16,24 & - & $-3,17$ \\
\hline & 2016 & 100 & 48,01 & - & - & 0,73 & 45,11 & - & 0,32 \\
\hline \multirow{2}{*}{$\begin{array}{l}\text { Caçapava do } \\
\text { Sul }\end{array}$} & $\Delta$ & 100 & $-7,65$ & $-0,06$ & $-5,69$ & $-6,82$ & 8,31 & $-0,11$ & 0,43 \\
\hline & 2016 & 100 & 25,39 & - & 0,14 & 2,21 & 48,93 & - & 1,28 \\
\hline \multirow{2}{*}{ Candiota } & $\Delta$ & 100 & $-18,58$ & - & $-2,19$ & $-19,55$ & 55,14 & - & $-6,02$ \\
\hline & 2016 & 100 & 7,41 & - & 0,43 & 5,03 & 66,28 & - & 1,82 \\
\hline \multirow{2}{*}{$\begin{array}{l}\text { Capão } \\
\text { Leão }\end{array}$} & $\Delta$ & 100 & $-3,89$ & $-0,15$ & $-0,04$ & $-5,16$ & 12,41 & $-0,27$ & $-0,01$ \\
\hline & 2016 & 100 & 72,05 & - & 0,01 & 1,49 & 26,34 & - & - \\
\hline \multirow{2}{*}{ Cerrito } & $\Delta$ & 100 & $-17,39$ & 0,48 & 0,18 & $-15,94$ & 49,34 & - & - \\
\hline & 2016 & 100 & 6,36 & 1,05 & 1,25 & 18,22 & 69,84 & - & - \\
\hline \multirow{2}{*}{ Chuí } & $\Delta$ & 100 & $-10,54$ & $-0,09$ & $-0,03$ & 0,11 & $-0,22$ & $-0,25$ & - \\
\hline & 2016 & 100 & 89,46 & 0,04 & 0,03 & 0,26 & 9,28 & 0,18 & - \\
\hline \multirow{2}{*}{ Dom Pedrito } & $\Delta$ & 100 & $-0,65$ & - & - & 0,28 & 7,03 & - & $-3,76$ \\
\hline & 2016 & 100 & 65,02 & - & - & 0,56 & 33,7 & - & - \\
\hline \multirow{2}{*}{ Hulha Negra } & $\Delta$ & 100 & $-1,83$ & $-1,69$ & $-0,71$ & $-22,56$ & 53,22 & $-12,05$ & $-1,48$ \\
\hline & 2016 & 100 & 14,78 & - & - & 1,55 & 80,1 & - & 0,37 \\
\hline \multirow{2}{*}{ Jaguarão } & $\Delta$ & 100 & $-19,77$ & $-0,04$ & 0 & $-0,29$ & 24,01 & - & $-3,01$ \\
\hline & 2016 & 100 & 64,65 & 0 & 0,01 & 0,82 & 31,66 & - & 1,33 \\
\hline \multirow{2}{*}{$\begin{array}{l}\text { Lavras do } \\
\text { Sul }\end{array}$} & $\Delta$ & 100 & $-9,96$ & $-0,14$ & $-0,47$ & $-8,89$ & 20,09 & $-0,1$ & 0,95 \\
\hline & 2016 & 100 & 19,77 & - & - & 0,73 & 75,93 & - & 3,57 \\
\hline \multirow{2}{*}{ Pedras Altas } & $\Delta$ & 100 & $-30,12$ & - & 0,04 & $-7,99$ & 49,71 & - & $-0,28$ \\
\hline & 2016 & 100 & 23,11 & - & 0,11 & 0,6 & 76,18 & - & - \\
\hline \multirow{2}{*}{$\begin{array}{l}\text { Pinheiro } \\
\text { Machado }\end{array}$} & $\Delta$ & 100 & $-2,75$ & $-0,01$ & 4,79 & $-5,77$ & 17,24 & - & $-3,51$ \\
\hline & 2016 & 100 & - & 0,42 & 10,43 & 24,87 & 58,16 & - & 2,22 \\
\hline \multirow{2}{*}{ Piratini } & $\Delta$ & 100 & $-5,24$ & $-0,39$ & $-1,77$ & $-14,25$ & 45,42 & - & $-6,54$ \\
\hline & 2016 & 100 & 4,83 & - & 0,6 & 4,06 & 83,0 & - & 1,35 \\
\hline \multirow{2}{*}{ Rio Grande } & $\Delta$ & 100 & $-0,25$ & $-6,69$ & $-0,01$ & 0,27 & 4,6 & 0,75 & - \\
\hline & 2016 & 100 & 86,44 & 4,77 & 0,01 & 0,29 & 5,23 & 1,27 & - \\
\hline \multirow{2}{*}{$\begin{array}{l}\text { Santana da } \\
\text { Boa Vista }\end{array}$} & $\Delta$ & 100 & $-2,03$ & - & $-9,95$ & $-17,84$ & 30,29 & $-0,23$ & 0,7 \\
\hline & 2016 & 100 & 1,85 & - & 0,49 & 2,11 & 90,52 & - & 0,97 \\
\hline \multirow{2}{*}{$\begin{array}{l}\text { Santa Vitória } \\
\text { do Palmar }\end{array}$} & $\Delta$ & 100 & $-8,27$ & 0 & - & 0,01 & 8,03 & $-0,02$ & - \\
\hline & 2016 & 100 & 91,65 & 0,01 & - & 0,02 & 8,19 & 0,03 & - \\
\hline
\end{tabular}

Fonte: PAM 2016 (IBGE - Dados organizados pelos autores).

A Tabela 4 desnuda um dos impactos da especialização produtiva, a preferência dos agricultores por uma cultura não-alimentar por esta apresentar 
maiores vantagens econômicas pois é uma commodity agrícola. Por isso recebe amplo apoio para ser produzida por ser o principal produto da pauta de exportação do Rio Grande do Sul. O Pronaf atrai o agricultor por sua rentabilidade ser satisfatória e seguramente garantida. (FEIX; LEUSIN JÚNIOR; AGRONONIK, 2017). Por sua vez, Wesz Júnior (2014) assinala que a Lei Kandir, promulgada em setembro de 1996, é mais um incentivo para a produção de um gênero agrícola que será exportado. A desoneração do Imposto sobre Circulação de Bens e Mercadorias (ICMS) nas exportações de matérias-primas fez com que aumentasse a competitividade das commodities agrícolas brasileiras no mercado internacional.

A análise da área plantada também colabora para identificar o caráter extremamente seletivo do cultivo agrícola nesses municípios que apresentam especialização produtiva. Observa-se no Gráfico 1 que, em média, em 2007, a área ocupada pelas culturas de soja e arroz era de $66 \%$ em relação à área com culturas temporárias. O restante do cultivo disputava um terço da área para plantio. A agricultura da região apresentou a coexistência do arroz e da soja herdada das décadas de 1960 e 1970 para o cultivo. Porém, no período atual a preferência foi invertida na maior parte dos municípios e a especialização fortemente aprofundada. Atualmente, somadas, essas lavouras ocupam mais de $90 \%$ da área disponível para cultivo na Zona Sul.

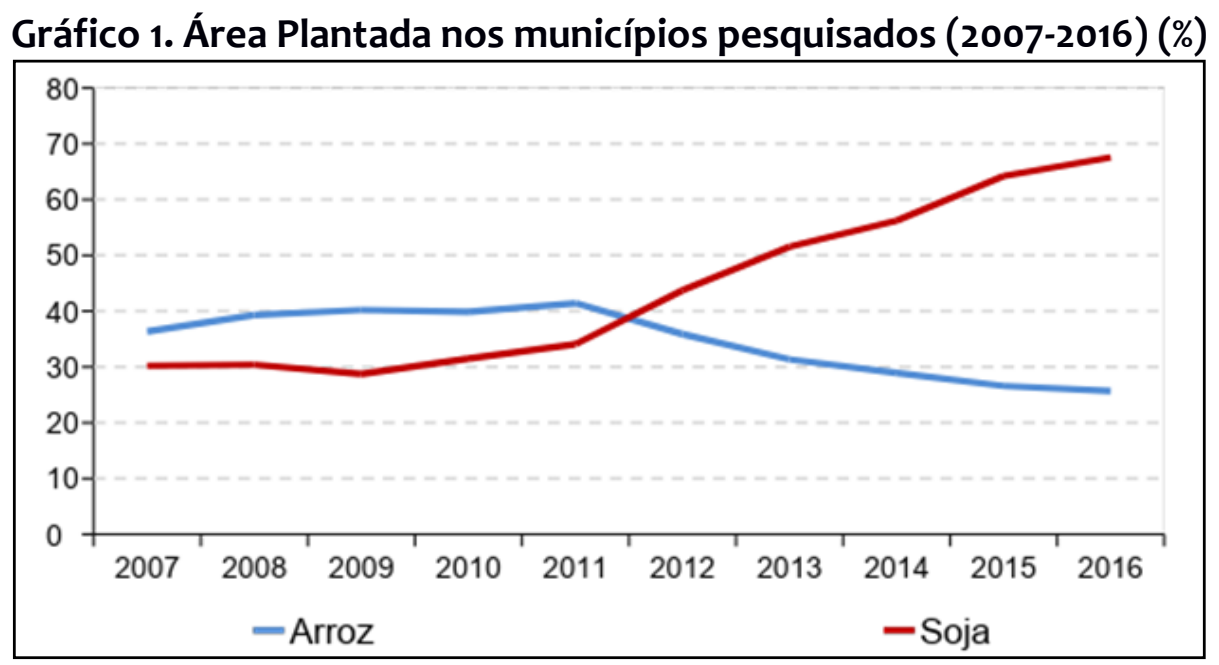

Fonte: MDCR - BCB (Dados organizados pelos autores).

Araújo (2011) assinala que a agricultura de caráter extensivo exige o aumento da área cultivada e mais máquinas e fertilizantes. Esse aumento da dependência de fatores de produção intensivos em terra e capital afasta o pequeno agricultor da cadeia produtiva. A agricultura familiar não é regida pelas categorias analíticas do capitalismo e esse tipo de agricultor tem dificuldade de inserção no mercado de commodities. Dessa forma, o uso da terra nos municípios da região mostra que há um direcionamento para a produção de um só produto agrícola aumentando os estabelecimentos praticantes de monocultivo e suas práticas comuns.

De acordo com o Censo Agropecuário de 2017, no Rio Grande do Sul, 71\% dos estabelecimentos agropecuários utilizam agrotóxicos e a média dos 38.693 estabelecimentos dos 29 municípios da região que não praticam agricultura ou 
pecuária orgânica é de 97,62\%. Com isso, percebe-se que a produção rural está cada vez mais tomada por métodos que se distanciam do uso sustentável dos recursos naturais. Com isso, de acordo com a classificação de Vennet, Schneider e Dessein (2015), o agricultor familiar empresarial é beneficiado por ser capaz de cumprir as exigências do mercado de commodities agrícolas.

\subsection{Financiamentos}

Os valores financiados e atualizados pelo Índice de Preços ao Consumidor Amplo (IPCA) de 2017 são apontados pelo Gráfico 2. Nele observa-se o caráter concentrador do crédito rural para custeio, fundamentalmente direcionado para a produção de soja.

\section{Gráfico 2. Valores financiados pelo Pronaf-custeio nos municípios selecionados} entre 2013 e 2017

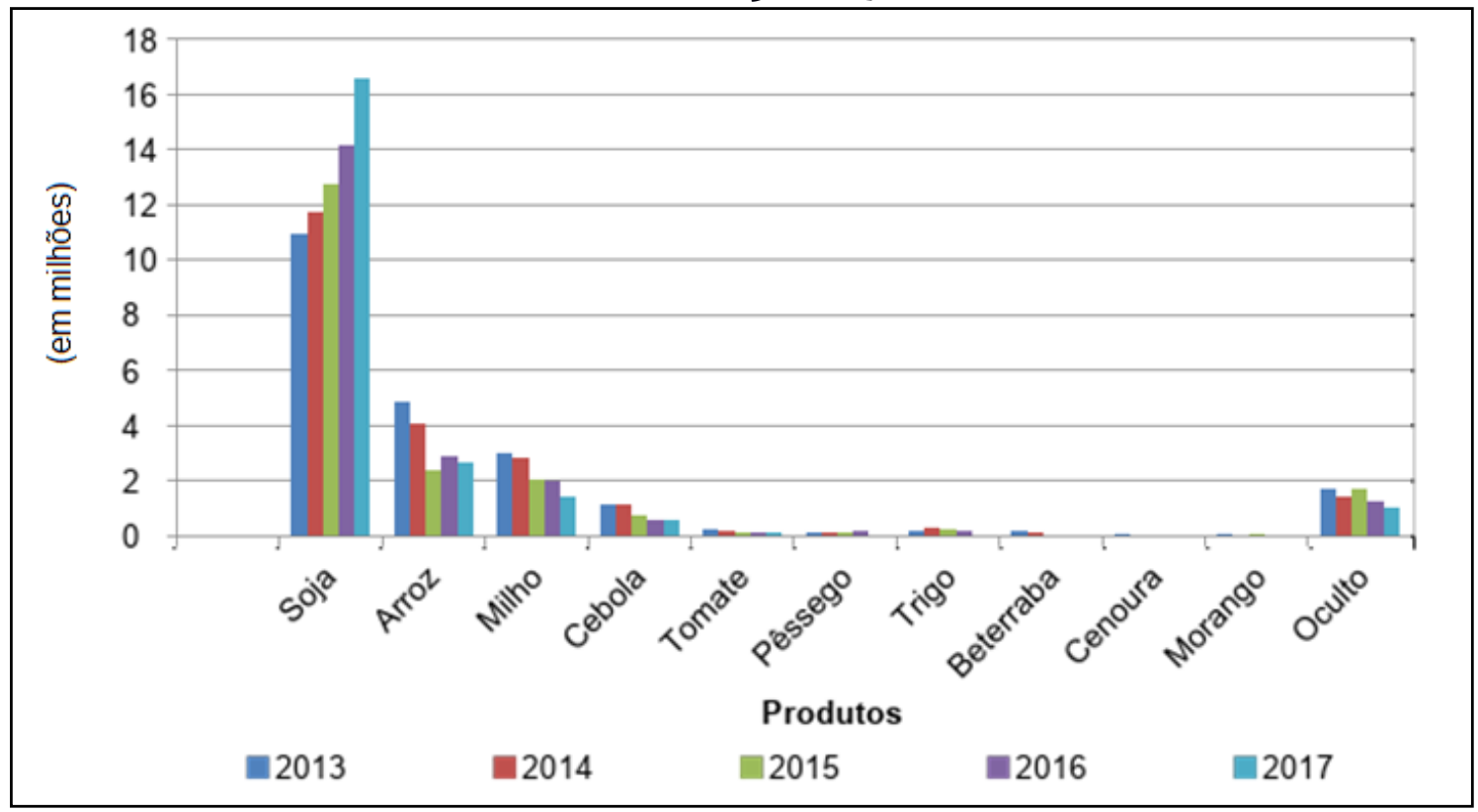

Fonte: MDCR - BCB (Dados organizados pelos autores).

Com base nesses dados, ao ser beneficiado com o crédito do Pronaf, o agricultor familiar torna-se mais um fornecedor de um produto que está na pauta de exportações do país, sinalizando que é mais atrativo abastecer o mercado externo do que o mercado interno ou nacional. $O$ cultivo de soja, além de compor a maior parte dos contratos da região, também concentra a maior parcela dos recursos financiados. Em 2013, a soja compunha aproximadamente $50 \%$ do valor financiado para a região, enquanto o arroz participava com $21,6 \%$ do valor coletado seguido pela cultura do milho com $13,3 \%$, da cebola com $5 \%$ e tomate com apenas $1,1 \%$. No final do período, o montante financiado para a soja era de $74,3 \%$. Arroz, milho, cebola e tomate tiveram suas participações reduzidas pela metade. Enquanto isso os outros produtos foram retirados da lista de financiamento. A parcela de produtos ocultos foi reduzida em quase 3\%. Em 2013 contava com 7,5\% dos financiamentos. Portanto, o financiamento do Pronaf direciona os agricultores para a produção de soja. 
Após a atualização monetária pelo Índice de Preços ao Consumidor Amplo (IPCA) verificou-se que tanto em 2013 quanto em 2017, o valor total financiado foi de $\mathrm{R} \$ 22,3$ milhões. A manutenção do valor financiado aos municípios da região indica que a forma de exploração das lavouras está apresentando sinais de esgotamento ao reduzir a produção alimentar. Com isso, o produtor de alimentos não tem apoio institucional para a melhoria de suas condições de produção e geração de renda.

Este financiamento concentrado na produção de grãos ao longo desses cinco anos gerou a redução de contratos por produto agrícola também. A Tabela 5 ilustra este fenômeno. É importante analisar que ao longo da coleta, observou-se a redução do número de contratos. A pesquisa iniciou com 898 contratos nos 17 municípios e terminou com 527 contratos. É importante salientar que 61 contratos de cebola e tomate de 2017 são registrados apenas no município de Rio Grande. Com isso fica evidente que a produção de alimentos não cabe nos financiamentos do programa nos moldes atuais. Enquanto os contratos por produtos foram reduzidos no período, os contratos das lavouras de soja quase duplicaram totalizando mais da metade dos compromissos firmados nos municípios observados.

Tabela 5. Contratos por produto do Pronaf-custeio

\begin{tabular}{lll}
\hline Produtos & 2013 & 2017 \\
\hline Soja & $27,3 \%$ & $52,0 \%$ \\
Arroz & $9,0 \%$ & $6,3 \%$ \\
Milho & $40,6 \%$ & $23,1 \%$ \\
Cebola & $11,1 \%$ & $9,1 \%$ \\
Tomate & $2,1 \%$ & $2,5 \%$ \\
Pêssego & $0,8 \%$ & - \\
Trigo & $0,4 \%$ & - \\
Beterraba & $1,4 \%$ & - \\
Cenoura & $0,6 \%$ & - \\
Morango & $0,4 \%$ & - \\
Oculto & $6,1 \%$ & $7,0 \%$ \\
\hline Total de contratos & 898 & 527 \\
\hline
\end{tabular}

Fonte: $M D C R-B C B$ (Dados organizados pelos autores).

A Tabela 6 mostra a diminuição do rol de produtos agrícolas financiados pelo Pronaf-custeio no período. A lista que inicia diversificada é reduzida pela metade totalizando apenas cinco produtos agrícolas. O agricultor familiar da região deixou de financiar a produção de pêssego, trigo, beterraba, cenoura e morango por meio do programa. No período, a produção de culturas alimentares tem perdido o espaço para a produção de soja, principalmente. Lamentavelmente, a PAM não possui dados para as culturas alimentares que o Pronaf-custeio financiou neste período. Destaca-se, porém, que no ano de 2013 o município de Rio Grande foi responsável pelos contratos envolvendo cebola, tomate, beterraba, cenoura e morango. Os sete contratos de cultivo de pêssego eram do município de Cerrito enquanto os quatro de trigo encontravam-se em Jaguarão. O restante dos contratos custeou a produção de soja, arroz e milho. 
Tabela 6. Produtos financiados pelo Pronaf-custeio entre 2013 e 2017

\begin{tabular}{|c|c|c|}
\hline Ano & Produtos & Culturas \\
\hline 2013 & 10 & $\begin{array}{l}\text { Soja, Arroz, Milho, Pêssego, Trigo, Cebola, Tomate, Beterraba, } \\
\text { Cenoura e Morango. }\end{array}$ \\
\hline 2014 & 8 & $\begin{array}{l}\text { Soja, Arroz, Milho, Pêssego, Trigo, Cebola, Tomate e } \\
\text { Beterraba. }\end{array}$ \\
\hline 2015 & 8 & Soja, Arroz, Milho, Pêssego, Trigo, Cebola, Tomate e Morango \\
\hline 2016 & 7 & Soja, Arroz, Milho, Pêssego, Trigo, Cebola e Tomate. \\
\hline 2017 & 5 & Soja, Arroz, Milho, Cebola e Tomate. \\
\hline
\end{tabular}

Fonte: MDCR - BCB (Dados organizados pelo autor).

Vennet, Schneider e Dessein (2015) confirmam que a produção de soja é comum a todos os tipos de agricultores familiares, mas o Pronaf falhou em deixar esse grupo de agricultores fazerem suas decisões apenas de acordo com os acenos do mercado. Uma das principais constatações (embora necessite de estudos mais aprofundados) é que a produção alimentar está sendo paulatinamente abandona pelo Pronaf. A manutenção de uma lavoura de soja tem custos altíssimos e o programa tem facilitado com que um grupo muito restrito de agricultores alcance a produção desse produto agrícola. Assim, o Pronaf atua em duas frentes. De um lado, o programa permite que um grupo de agricultores familiares capitalizados acesse um mercado que não seria possível sem o auxílio financeiro do programa e, de outro, a agricultura convencional recebe o suporte dos agricultores familiares que possibilitam a redução de custos da produção de soja.

O sucesso do Pronaf nos últimos 20 anos deve ser visto com ressalvas. Ele possibilitou que muitos agricultores acessassem linhas de crédito rural antes não acessíveis. Porém esse processo teve o custo do distanciamento do agricultor familiar das características idealizadas de quando o programa foi elaborado na década de 1990. Guanzirolli (2007) aponta que o efeito spill over não ocorreu. A focalização dos financiamentos em agricultores familiares do Grupo Variável não tornou possível o aumento da demanda por emprego dos agricultores familiares periféricos dentro do Pronaf. Com isso, nota-se que o programa parece sinalizar distanciamento perigoso no que diz respeito à produção de não commodities nos municípios analisados.

\section{Considerações finais}

Em vinte anos, o Pronaf mostrou-se a principal política pública de apoio aos agricultores familiares, embora com certa timidez no que diz respeito às estruturas produtivas do rural brasileiro. Também cabe registrar que, em linhas gerais, as políticas de financiamento fora do escopo do Pronaf são ainda mais agressivas no que diz respeito à especialização produtiva e concentração de renda setorial. $O$ Pronaf deve ser repensado enquanto principal política pública que aporta recursos aos agricultores familiares no sentido de apoiar a diversificação produtiva e a agregação de valor. Em nenhuma hipótese deve-se imaginar a suspensão do Pronaf, pois isso acarretaria em prejuízos extraordinários aos agricultores e às economias 
locais e regionais. Da crítica devemos colher decisões inteligentes, que não expurguem os agricultores familiares das já parcas políticas públicas existentes. $O$ diagnóstico não deve servir para matar o paciente. Diagnosticar a realidade deve servir, antes de mais nada, para atacar as causas e não as consequências. O Pronaf é fundamental para a agricultura familiar brasileira, mas necessitamos dialogar sobre o que a sociedade brasileira espera da sua agricultura, especialmente a de base familiar.

Na Zona Sul do Rio Grande do Sul, essa política pública apresenta-se afastada de seu propósito inicial fazendo aquilo que a literatura denominou "mais do mesmo". As práticas agrícolas não condizem com o que está escrito na Lei da Agricultura Familiar de 2006 e nem no decreto fundador do Pronaf em 1996. Os resultados mostram que o aumento da participação da soja nos financiamentos do Pronaf-custeio no intervalo de cinco anos aponta para a distorção de um programa que tinha como foco reduzir as desigualdades no meio rural brasileiro.

Por sua vez, nos municípios especializados em soja e arroz da Zona Sul, o Pronaf-custeio aprofunda a concentração produtiva fortalecendo o cultivo de soja. No lugar de ampliar os produtos cultivados pelos agricultores familiares da região, o Pronaf-custeio estreita as opções de atividades geradoras de renda no meio rural. Esta política direciona a agricultura familiar para se tornar linha auxiliar do agronegócio, agravando as desigualdades no campo e os impactos ambientais, com o uso, cada vez maior de agrotóxicos, ampla possibilidade de asseverar a segurança alimentar e nutricional local e regional, aumentando assim a vulnerabilidade social dos pobres do meio rural da região.

\section{REFERÊNCIAS}

AQUINO, J.R.; SCHNEIDER, S.. 12 Anos de crédito do PRONAF no Brasil (1996-2008): Uma reflexão crítica. Revista de Extensão e Estudos Rurais, Viçosa, v. 1, n. 2, p.309347, jul. 2011. Semestral.

BANCO CENTRAL DO BRASIL. Matriz de Dados do Crédito Rural. Brasília, 2018.

BANDEIRA, P. S.. As raízes históricas do declínio da Região Sul. In: ALONSO, J. A. F.; BENETTI, M. D.; BANDEIRA, P. S.. Crescimento econômico da Região Sul do Rio Grande do Sul: causas e perspectivas. Porto Alegre: Fundação de Economia e Estatística Siegfried Emanuel Heuser, 1994. Cap. 1. p. 7-48.

BENETTI, M. D.. Agropecuária na Região Sul do Rio Grande do Sul - 1970-90. In: ALONSO, J. A. F.; BENETTI, M. D.; BANDEIRA, P. S.. Crescimento econômico da Região Sul do Rio Grande do Sul. Porto Alegre: Fundação de Economia e Estatística Siegfried Emanuel Heuser, 1994. Cap. 3. p. 95-212.

BIANCHINI, V.. Vinte anos do Pronaf, 1995-2015: avanços e desafios. Brasília: SAF/MDA, 2015. $113 \mathrm{p}$.

BRASIL, Ministério do Meio Ambiente. Relatório Biomas. 2017. 
COPETTI, L. D.. Fatores que dificultam o acesso dos agricultores familiares às políticas de crédito rural: o caso do Pronaf-crédito no município de Alegria-RS. 2008. 206 f. Dissertação (Mestrado) - Curso de Desenvolvimento Rural, Universidade Federal do Rio Grande do Sul, Porto Alegre, 2008.

CUNHA, A. S. (coord.). da. Uma avaliação da sustentabilidade da agricultura nos cerrados. Estudos de Politica Agricola. Relatorios de Pesquisa, 11. Brasilia: IPEA, 1994.204 p.

DELGADO, G. C.. Do Capital Financeiro na Agricultura à Economia do Agronegócio: Mudanças cíclicas em meio século (1965-2012). Porto Alegre: Editora da Ufrgs, 2012. 144 p.

FEEDADOS, Fundação de Economia e Estatística. Dados Municipais, 2015. http://feedados.fee.tche.br/ Acesso em 12 de janeiro de 2019

FEIX, R. D.; LEUSIN JÚNIOR, S.; AGRANONIK, C.. Painel do Agronegócio no Rio Grande do Sul - 2017. Porto Alegre: Fundação de Economia e Estatística Siegfried Emanuel Heuser, 2017. 55 p.

FURTADO, C.. Formação Econômica do Brasil. 32. ed. São Paulo: Companhia Editora Nacional, 2005. 238 p.

FLEXOR, G.; LEITE, S.P.. Land Market and Land Grabbing in Brazil during the Commodity Boom of the 2000s. Contexto Internacional, vol. 39(2) May/Aug 2017 http://dx.doi.org/10.1590/S0102-8529.2017390200010

GARAGORRY, F.L.; ALVES, E.; SOUZA, G.S.. Tipos de especialização na agricultura brasileira. Revista Brasileira de Economia, [s.I.], v. 57, n. 2, p.337-369, jun. 2003. FapUNIFESP (SciELO).

GAZOLLA, M.; SCHNEIDER, S.. Qual "fortalecimento" da agricultura familiar?: uma análise do Pronaf crédito de custeio e investimento no Rio Grande do Sul. RESR, Piracicaba, v. 51, n. 1, p.46-70, abr. 2013. Trimestral.

GODOI, T.G.; BÚRIGO, F.L.; CAZELLA, A.A.. A sustentabilidade dos financiamentos do PRONAF para agricultura familiar. Desenvolvimento e Meio Ambiente, Curitiba, v. 38, p.637-661, ago. 2016. Semestral.

GRISA, C.. A agricultura familiar nas políticas para a agricultura familiar no Brasil. In: DELGADO, G.C.; BERGAMASCO, S.M.P.P.. Agricultura familiar brasileira: desafios e perspectivas de futuro. Brasília: Ministério do Desenvolvimento Agrário, 2017. p. 290-308.

GRISA, C.; WESZ JÚNIOR, V.J.; BUCHWEITZ, V.D.. Revisitando o Pronaf: velhos questionamentos, novas interpretações. Revista de Economia e Sociologia Rural RESR, Piracicaba, v. 52, n. 2, p.323-346, abr. 2014. Trimestral. 
GUANZIROLLI, C.. PRONAF dez anos depois: resultados e perspectivas para o desenvolvimento rural. RER, Rio de Janeiro, v. 45, n. 2, p.301-328, abr. 2007. Trimestral.

IBGE, Instituto Brasileiro de Geografia e Estatística. Mapa de Biomas do Brasil,Brasília, 2004.

. Censo Agropecuário 1996-2006,Brasília, 2006.

. Censo Agropecuário 2017,Brasília, 2018.

- Produção Agrícola Municipal,Brasília, 2016.

KAGEYAMA, A.. Desenvolvimento Rural: conceito e medida. Cadernos de Ciência \& Tecnologia, Brasília, v. 21, n. 3, p.379-308, dez. 2004. Trimestral.

KUPLICH, T.M., CAPOANE, V.; COSTA, L.F.F. O avanço da soja no bioma Pampa. Boletim Geográfico do Rio Grande do Sul, Porto Alegre, n. 31, p. 83-100, jun. 2018

MOREIRA, J.G.. Pecuária e soja no pampa brasileiro: disputas e complementariedades. 2019. 92 f. Dissertação (Mestrado) - Curso de Desenvolvimento Rural, Universidade Federal do Rio Grande do Sul, Porto Alegre, 2019.

OLIVEIRA, G.; KÜHN, D.D.; PEREIRA, A.S.. O papel da especialização agrícola no desenvolvimento humano e no crescimento econômico regional. Passo Fundo: Centro de Pesquisa e Extensão Feac, 2009. 28 p.

PAULINO, E.T.; KRÜGER, C. R.. Agricultura empresarial e produção camponesa no contexto das disputas territoriais recentes: o caso paranaense. Acta Scientiarum. Human And Social Sciences, [s.l.], v. 32, n. 1, p.97-107, 16 dez. 2009. Universidade Estadual de Maringa.

PIRES, M. J. S.. Contradições em processo: um estudo da estrutura e evolução do Pronaf de 2000 a 2010. Brasília: Livraria do Ipea, 2013. 68 p.

PIZZATO, F.. Pampa gaúcho: causas e conseqüências do expressivo aumento das áreas de soja. 2013. 105 f. Dissertação (Mestrado) - Programa de Pós-Graduação em Geografia, Universidade Federal do Rio Grande do Sul, Porto Alegre, 2013.

PTRDS. Plano Territorial de Desenvolvimento Rural Sustentável: Território da Cidadania Zona Sul do Estado do Rio Grande do Sul. Pelotas: Centro de Apoio Ao Pequeno Agricultor, 2009. $68 \mathrm{p}$.

SCHNEIDER, S.; CASSOL, A.. A agricultura familiar no Brasil. Porto Alegre: Desconhecida, 2013. $70 \mathrm{p}$. 
TOLENTINO, M. L. D. L. Da revolução verde ao discurso do Pronaf: a representação do desenvolvimento nas políticas públicas de desenvolvimento rural no Brasil. Revista Cerrados, Montes Claros, v. 14, n. 2, p.97-124, jan. 2017. Semestral.

VENNET, B.V.; SCHNEIDER, S.; DESSEIN, J.. Different farming styles behind the homogenous soy production in southern Brazil. The Journal of Peasant Studies, 2015. DOI: 10.1080/03066150.2014.993319

WESZ JÚNIOR, W.J.. O mercado da soja e as relações de troca entre produtores rurais e empresas no Sudeste de Mato Grosso (Brasil). 2014, 237 f. Tese (Doutorado). Curso de Ciências Sociais em Desenvolvimento, Agricultura e Sociedade, Universidade Federal Rural do Rio de Janeiro, Rio de Janeiro, 2014.

.Strategies and hybrid dynamics of soy transnational companies in the Southern Cone. The Journal of Peasant Studies, 43:2, 286-312, 2016. DOI: 10.1080/03066150.2015.1129496

Marcelo Antonio Conterato. Graduado em Geografia (UFSM), mestre e doutor em Desenvolvimento Rural. Professor do Departamento de Economia e Relações Internacionais (DERI/UFRGS) e do Programa de Pós-Graduação em Desenvolvimento Rural (PGDR/UFRGS).marcelo.conterato@ufrgs.br

Cauê Assis Bráz. Economista (UFRGS) e mestrando em Desenvolvimento Rural (PGDR/UFRGS).caueabraz@gmail.com produtiva dos agricultores familiares da Zona Sul do Rio Grande do Sul através do Pronafcusteio. Redes, Santa Cruz do Sul, v. 24, n. 3, p. 12-34, set. 2019. ISSN 1982-6745. Disponível em: https://doi.org/10.17058/redes.v24i3.14001. 